\title{
Stabilizing Lithium and Sodium Fast-Ion Conduction in Solid Polyhedral-Borate Salts at Device-Relevant Temperatures
}

\begin{abstract}
By a variety of techniques including $X$-ray powder diffraction, quasielastic neutron scattering, and AC impedance, we have probed the effect of mechanical milling on the phase behaviors of the different lithium and sodium closo-borate salt compounds containing $\mathrm{B}_{12} \mathrm{H}_{12}{ }^{2-}, \mathrm{B}_{10} \mathrm{H}_{10}{ }^{2-}$, and $\mathrm{CB}_{11} \mathrm{H}_{12}$ anions. We have found that the crystallite-size reduction and disordering effects of such milling enables the room- $T$ stabilization of their high- $T$-like superionic-conducting phases. This demonstrates a viable strategy for better exploiting the impressive cation mobilities that are typically restricted to somewhat higher temperatures for this class of compounds.
\end{abstract}

Keywords: Ball-milling; Closo-borate; Nanostructure; Phase Transition; Superionic Conductor

\section{Graphical Abstract}

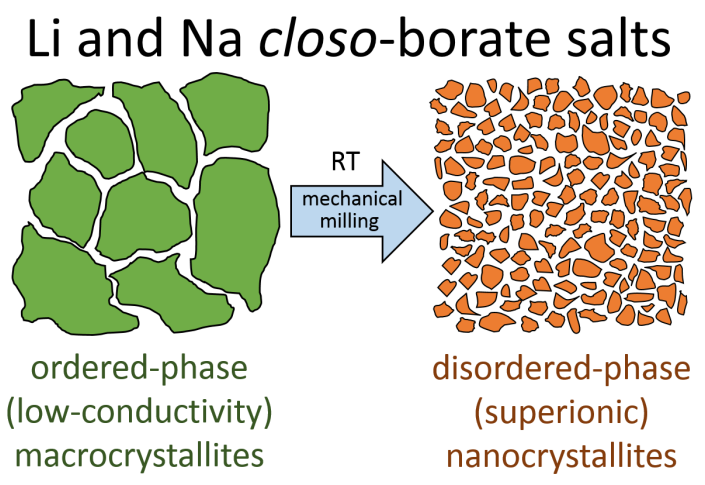

\section{Introduction}

Most of today's rechargeable batteries operate with liquid organic electrolytes, which not only present challenges concerning such matters as capacity fade and overall cycle life, but also make these batteries inherently prone to possible leakage, flammability, and Li-dendrite penetration and shorting. There has been a push to develop alternative solid-electrolyte technologies to address these concerns. One broad class of materials that has recently gained notice involves ionic compounds with complex hydride anions [1]. These compounds typically undergo order-disorder-type phase transitions to fast-ion-conducting structures with orientationally mobile anions, 
$\mathrm{LiBH}_{4}$ being one prototypical example [2]. These structures are aided by the configurational entropy increase that accompanies the orientational disordering of the polyatomic anions and site disordering of the cations.

More recently, we have shown that an increase in complex-hydride-anion size has a markedly positive effect on the fast-ion conductivity of the disordered phase. Indeed, the closo-borate compounds $\mathrm{Na}_{2} \mathrm{~B}_{12} \mathrm{H}_{12}$ [3], $\mathrm{Na}_{2} \mathrm{~B}_{10} \mathrm{H}_{10}$ [4] $\mathrm{NaCB}_{11} \mathrm{H}_{12}$ [5], $\mathrm{LiCB}_{11} \mathrm{H}_{12}$ [5], $\mathrm{NaCB}_{9} \mathrm{H}_{10}$ [6], and $\mathrm{LiCB}_{9} \mathrm{H}_{10}[6]$ with their overly large, cage-like anions exhibit exceptional ionic conductivities of $\sim 0.1 \mathrm{~S} \mathrm{~cm}^{-1}(540 \mathrm{~K}), 0.01 \mathrm{~S} \mathrm{~cm}^{-1}(383 \mathrm{~K}), 0.12 \mathrm{~s} \mathrm{~cm}^{-1}$ $(383 \mathrm{~K}), 0.15 \mathrm{~S} \mathrm{~cm}^{-1}(403 \mathrm{~K}), 0.05 \mathrm{~S} \mathrm{~cm}^{-1}(323 \mathrm{~K})$, and $0.04 \mathrm{~S} \mathrm{~cm}^{-1}(357 \mathrm{~K})$, respectively, just above their phase transition temperatures $T_{\text {trans. }}$. The high cation mobilities are presumably aided by the spacious (and partially vacant) interstitial pathways afforded by the packing arrangement of the orientationally mobile, $\mathrm{B}_{12} \mathrm{H}_{12}{ }^{2-}, \mathrm{B}_{10} \mathrm{H}_{10}{ }^{2-}, \mathrm{CB}_{11} \mathrm{H}_{12}$, and $\mathrm{CB}_{9} \mathrm{H}_{10}{ }^{-}$anions $[3,4,5,6,7,8,9,10]$. Similar exceptional ionic conductivities are expected for the $\mathrm{Li}_{2} \mathrm{~B}_{12} \mathrm{H}_{12}$ and $\mathrm{Li}_{2} \mathrm{~B}_{10} \mathrm{H}_{10}$ analogs, but only well in excess of $600 \mathrm{~K}[7,9,11,12]$.

Despite the high ionic conductivities of the binary closo-borate compounds, their widespread commercial use as solid electrolytes requires a strategy to stabilize their superionic disordered structures at lower device-relevant temperatures, i.e., at $295 \mathrm{~K}$ and below. Besides a possible reduction in $T_{\text {trans }}$ via appropriate chemical modifications, we found [5] that low- $T$ stabilization of these superionic structures could be realized by morphological modification, via ball-milling, which is known to reduce the crystallite size in solids as well as introduce nano-defects such as vacancies, interstitial sites, dislocations, grain boundaries and stacking faults. This is in line with a recent $\mathrm{Li}_{2} \mathrm{~B}_{12} \mathrm{H}_{12}$ study, which reported fast-ion conductivity at room temperature after only briefly milling the material, albeit at high energy [13]. This stabilization is not uncommon. Ballmilling of rutile $\mathrm{MgH}_{2}$, e.g., leads to the low- $T$ stabilization of high- $T$ orthorhombic $\gamma$-phase [14]. Corundum $\alpha$-phase $\mathrm{Al}_{2} \mathrm{O}_{3}$ adopts the higher-entropy $\gamma$-phase polymorph when the crystallites are nanosized [15]. Finally, $\mathrm{Li}_{3} \mathrm{~N}$ is known to adopt its higherpressure $\beta$-phase polymorph when confined inside carbon nanopores [16].

Here we report the room- $T$ stabilization, by ball-milling, of high- $T$-like disordered phases for all lithium and sodium closo-borate compounds studied, namely: $\mathrm{Li}_{2} \mathrm{~B}_{12} \mathrm{H}_{12}$, $\mathrm{Li}_{2} \mathrm{~B}_{10} \mathrm{H}_{10}$, $\mathrm{LiCB}_{11} \mathrm{H}_{12}, \mathrm{Na}_{2} \mathrm{~B}_{12} \mathrm{H}_{12}, \mathrm{Na}_{2} \mathrm{~B}_{10} \mathrm{H}_{10}$, and $\mathrm{NaCB}_{11} \mathrm{H}_{12}$. Select AC impedance measurements for ball-milled $\mathrm{Na}_{2} \mathrm{~B}_{12} \mathrm{H}_{12}$ and $\mathrm{Li}_{2} \mathrm{~B}_{12} \mathrm{H}_{12}$ confirmed dramatic increases in room- $T$ ionic conductivities compared to the pristine materials. In addition, we found that ball-milling mixtures of these materials can lead to mixed-polyhedral-anion compounds as well as room- $T$ stabilization of their own disordered phases. The success of such morphological modification with the additional potential to tailor the anion (and 
cation) composition opens up exciting new avenues for exploiting the impressive superionic properties associated with these large-anion materials.

\section{Experimental Details}

$\mathrm{Li}_{2} \mathrm{~B}_{12} \mathrm{H}_{12}, \mathrm{LiCB}_{11} \mathrm{H}_{12}, \mathrm{Na}_{2} \mathrm{~B}_{12} \mathrm{H}_{12}, \mathrm{Na}_{2} \mathrm{~B}_{10} \mathrm{H}_{10}$, and $\mathrm{NaCB}_{11} \mathrm{H}_{12}$ were obtained from Katchem. $\mathrm{Li}_{2} \mathrm{~B}_{10} \mathrm{H}_{10}$ was synthesized as reported in Ref. [12]. ${ }^{11} \mathrm{~B}$-enriched $\mathrm{Na}_{2}{ }^{11} \mathrm{~B}_{12} \mathrm{H}_{12}$ (preferred for neutron scattering experiments) was prepared according to Ref. [8]. $\mathrm{Na}_{2}{ }^{11} \mathrm{~B}_{12} \mathrm{H}_{12}$ was used for all pure $\mathrm{Na}_{2} \mathrm{~B}_{12} \mathrm{H}_{12}$ compound data presented. Natural-boron $\mathrm{Na}_{2} \mathrm{~B}_{12} \mathrm{H}_{12}$ was used to prepare a $\mathrm{Na}_{2} \mathrm{~B}_{12} \mathrm{H}_{12} / \mathrm{Na}_{2} \mathrm{~B}_{10} \mathrm{H}_{10}$ mixed compound. All compounds were dried under appropriate conditions of vacuum, time, and temperature $[4,5,7,12]$. The resulting anhydrous compounds were ball-milled using a Fritch Pulverisette no. 7 planetary ball mill at $400 \mathrm{~Hz}$. The total processing times were comprised of repetitive two-step sequences, which varied by material. Stainless steel vials (12 mL) with six $10 \mathrm{~mm}$ balls and six $1 \mathrm{~mm}$ balls per vial were typically used with sample masses of $\sim 0.3-0.4 \mathrm{~g}$.

Compounds before and after ball-milling were structurally characterized by X-ray powder diffraction (XRD) using a Rigaku Ultima III X-ray diffractometer with a Cu-K $\alpha$ source $(\lambda=1.5418 \AA$ ). Structural refinements were performed using the Fullprof software [17]. Various neutron scattering measurements of pristine and ball-milled $\mathrm{Na}_{2}{ }^{11} \mathrm{~B}_{12} \mathrm{H}_{12}$ were performed at the National Institute of Standards and Technology Center for Neutron Research. Quasielastic neutron scattering (QENS) measurements were taken on both the Disc Chopper Spectrometer (DCS) using incident neutrons of 12 $\AA$ 解 wavelength $(0.57 \mathrm{meV})$ with a full-width-at-half-maximum (fwhm) resolution of $11 \mu \mathrm{eV}$, and the High-Flux Backscattering Spectrometer (HFBS) using $6.27 \AA$ neutrons with a fwhm resolution of $0.8 \mu \mathrm{eV}$. HFBS fixed-window scans were collected at $\pm 0.5 \mathrm{~K}$ $\mathrm{min}^{-1}$ ramp rates. All neutron inelastic scattering data were analyzed using the DAVE software package [18]. Ionic conductivities were determined under Ar by the AC complex impedance method with a two-probe technique using an NF 5097 frequency response analyzer over a frequency range of $1 \mathrm{~Hz}$ to $10 \mathrm{MHz}$. The powder samples were pressed into pellets of $5 \mathrm{~mm}$ in diameter and approximately $2 \mathrm{~mm}$ in thickness without sintering, yielding densities typically more than $93 \%$ of those calculated from the lattice parameters. Au foils were used as electrodes for both $\mathrm{Na}_{2} \mathrm{~B}_{12} \mathrm{H}_{12}$ and $\mathrm{Li}_{2} \mathrm{~B}_{12} \mathrm{H}_{12}$ and mechanically fixed onto both faces of the pellets.

N.B., standard uncertainties for all figures in the text and Supplementary Material are commensurate with the observed scatter in the data, if not explicitly designated by vertical error bars. 


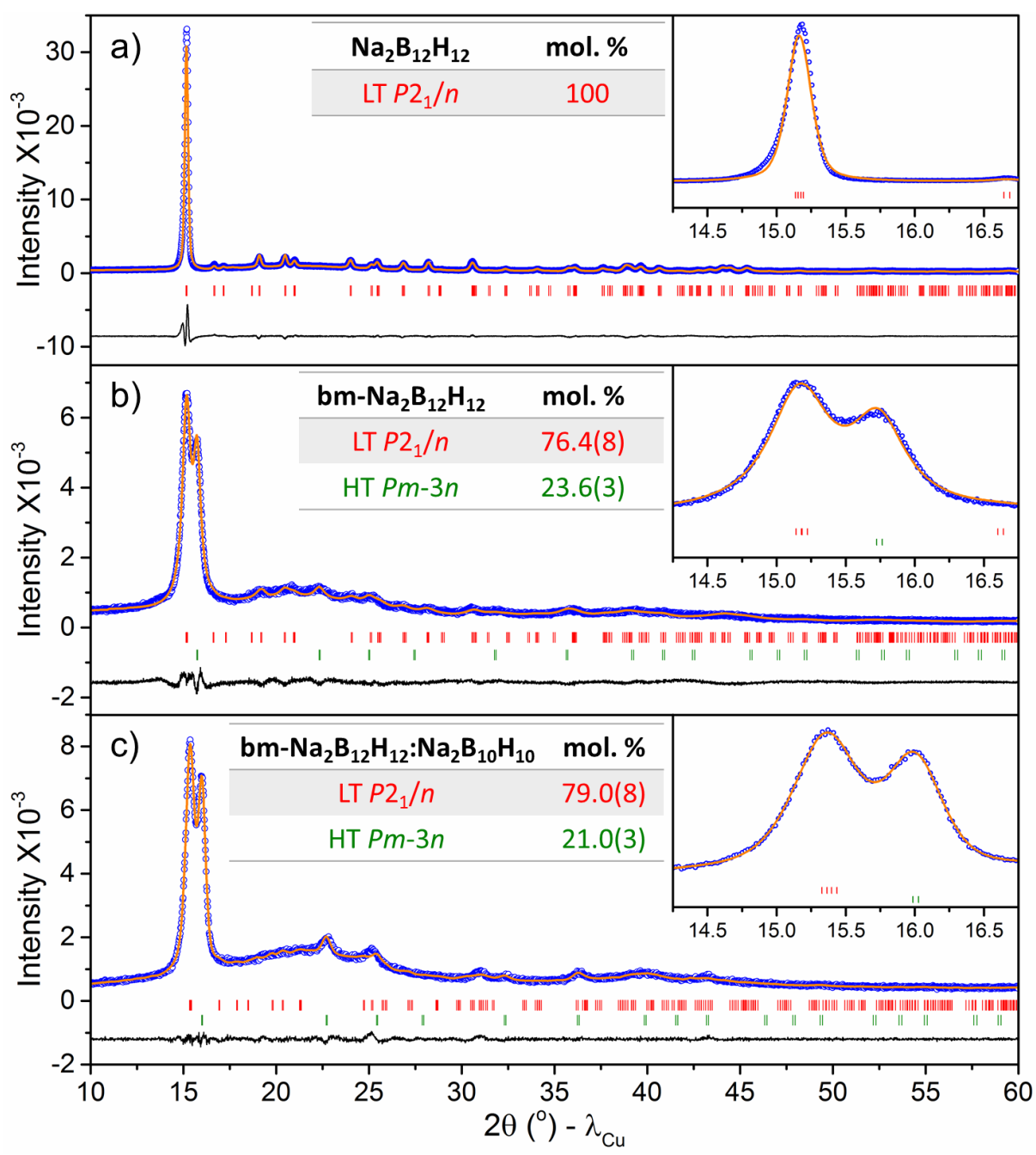

Fig. 1. Room- $T$ XRD data [experimental (blue circles), fitted (orange line), and difference (black line) patterns] for (a) pristine $\mathrm{Na}_{2} \mathrm{~B}_{12} \mathrm{H}_{12}$, (b) ball-milled $\mathrm{Na}_{2} \mathrm{~B}_{12} \mathrm{H}_{12}$, and (c) ball-milled 1:1 $\mathrm{Na}_{2} \mathrm{~B}_{12} \mathrm{H}_{12}: \mathrm{Na}_{2} \mathrm{~B}_{10} \mathrm{H}_{10}$. Red and green bars indicate the positions of Bragg peaks for the low-T monoclinic and high-T pseudo-bcc phases, respectively; refinement-derived phase fractions are listed. See Supplementary Material for more details.

\section{Results and Discussion}

Figs. $1 \mathrm{a}$ and $1 \mathrm{~b}$ depict representative $\mathrm{X}$-ray powder diffraction (XRD) patterns for $\mathrm{Na}_{2} \mathrm{~B}_{12} \mathrm{H}_{12}$ before and after ball-milling for $72 \mathrm{~h}$. (See Table S1 and Figs. S1-S8) for ballmilling details and corresponding XRD results for the other compounds studied.) As exemplified here, ball-milling introduces substantial Bragg peak broadening in all studied compounds. Moreover, phase analyses of the post-ball-mill patterns by Rietveld refinement are consistent with the presence of two phases in all cases, the expected low- $T$ ordered phase plus what appears to be a higher-symmetry disordered phase matching that normally observed above the order-disorder phase transition. For $\mathrm{Na}_{2} \mathrm{~B}_{12} \mathrm{H}_{12}$, the ordered phase has monoclinic symmetry, whereas the disordered phase has body-centered-cubic (bcc) symmetry [7]. After ball-milling, the molar ratio of ordered-to-disordered phases was estimated from refinement to be 76:24. Complementary neutron powder diffraction (NPD) measurements (Fig. S9) confirmed 
that the disordered bcc fraction remained stable down to at least $5 \mathrm{~K}$, and neutron vibrational spectra (Fig. S10) revealed minor phonon perturbations due to this disorder.

Fig. S11 displays representative scanning electron microscopy images of both $\mathrm{Na}_{2} \mathrm{~B}_{12} \mathrm{H}_{12}$ and $\mathrm{Li}_{2} \mathrm{~B}_{12} \mathrm{H}_{12}$ before and after ball-milling, elucidating the milling-induced particle pulverization. For all these materials, it is clear that increasing the fraction of superionic phase will depend on more aggressive milling conditions or more efficient and thorough ways to maximize the necessary nanoparticulate morphologies. For example, we noticed in our past investigations to create modified materials by infiltrating smaller anions into the polyhedral salt structures via ball-milling, that these additional salt compounds potentially acted as "abrasives" to enhance the particle-size reduction, leading to much higher fractions of disordered phase. This is exemplified in Fig. S6 by the XRD pattern for a $1: 1 \mathrm{Na}_{2} \mathrm{~B}_{10} \mathrm{H}_{10}: \mathrm{Na}_{2} \mathrm{CO}_{3}$ mixture ball-milled for $28 \mathrm{~h}$, indicating that $82 \%$ of the $\mathrm{Na}_{2} \mathrm{~B}_{10} \mathrm{H}_{10}$ is in its disordered fcc phase at room temperature, compared with only around $27 \%$ after ball-milling for $80 \mathrm{~h}$ without any additive (Fig. S2). Differential scanning calorimetry (Fig. S12) confirmed no order-disorder phase transition upon cycling until the sample was annealed to $\sim 550 \mathrm{~K}$, presumably leading to increased particle sizes and reduced defects through accelerated sintering. This additive-assisted particle-size reduction was even observed at the lowest $\mathrm{Na}_{2} \mathrm{CO}_{3}$ doping of $5 \%$ and for other additives such as $\mathrm{Na}_{2} \mathrm{SO}_{4}$.

Fig. 1c shows the room- $T$ XRD pattern for a $1: 1$ mixture of $\mathrm{Na}_{2} \mathrm{~B}_{12} \mathrm{H}_{12} / \mathrm{Na}_{2} \mathrm{~B}_{10} \mathrm{H}_{10}$ after ball-milling for $4 \mathrm{~h}$ followed by vacuum annealing at $548 \mathrm{~K}$ for $16 \mathrm{~h}$. This pattern is reminiscent of that for ball-milled $\mathrm{Na}_{2} \mathrm{~B}_{12} \mathrm{H}_{12}$ in Fig. $1 \mathrm{~b}$. Indeed, it is in line with the presence of both ordered monoclinic and disordered bcc solid-solution phases (each containing both $\mathrm{B}_{12} \mathrm{H}_{12}{ }^{2-}$ and $\mathrm{B}_{10} \mathrm{H}_{10}{ }^{2-}$ anions) with unit cell volumes intermediate between the ordered/disordered volumes of the pure compounds (see Fig. S7 for more details). Hence, this strongly suggests that nanocrystalline mixed-polyhedral-anion compounds can also be synthesized in this way, resulting in the room- $T$ stabilization of their own disordered alloy phases.

Quasielastic neutron scattering (QENS) measurements for the same pre- and post-ball-milled ( ${ }^{11} \mathrm{~B}$-labelled) $\mathrm{Na}_{2} \mathrm{~B}_{12} \mathrm{H}_{12}$ sample measured by XRD in Fig. 1 are shown in Fig. 2. The temperature behavior of the neutron fixed-window scans (FWSs) in Fig. $2 a$ reflect $\mathrm{B}_{12} \mathrm{H}_{12}{ }^{2-}$ anion reorientational jump frequencies on the order of $10^{8} \mathrm{~s}^{-1}$ already by 240-250 K after ball-milling (as evidenced by the onset of more significant intensity dropoff), which is consistent with the presence of the high-T-like disordered phase manifested by XRD. In comparison, pristine $\mathrm{Na}_{2} \mathrm{~B}_{12} \mathrm{H}_{12}$ displays hysteretic FWS behavior and high reorientational mobility only at considerably higher temperatures, as 

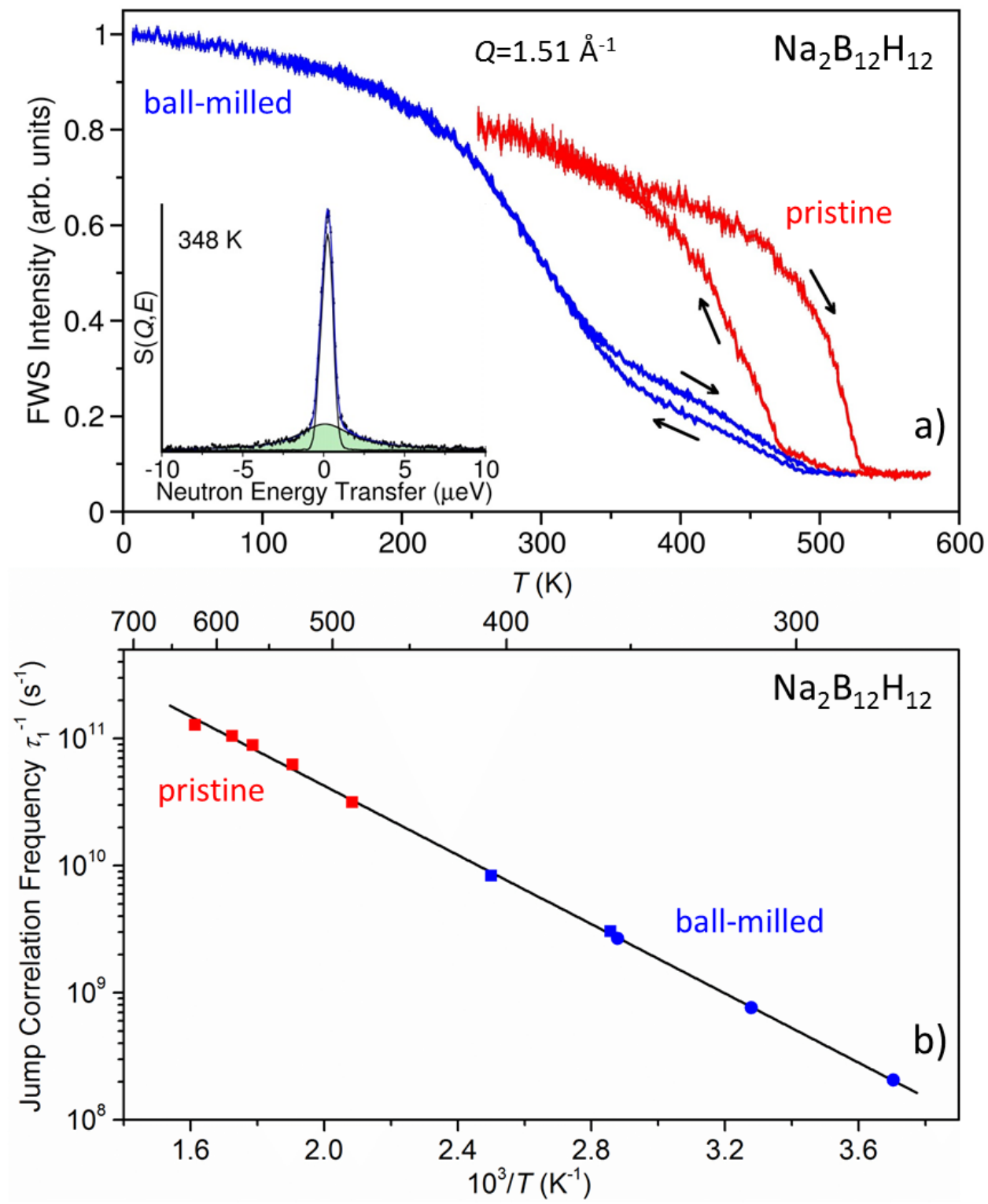

Fig. 2 (a) Neutron fixed-window scans (HFBS, neutron momentum transfer $Q=1.51 \AA^{-1}$ ) for $\mathrm{Na}_{2} \mathrm{~B}_{12} \mathrm{H}_{12}$ before (red) and after (blue) ball-milling for $72 \mathrm{~h}$. Inset: QENS spectrum ( $\left.348 \mathrm{~K}, Q=1.51 \AA^{-1}\right)$ showing Lorentzian broadening (green) due to rapid anion reorientational motions $\left(\sim 3 \times 10^{9}\right.$ jumps s$\left.^{-1}\right)$ for the ball-milled material. (b) Arrhenius plot of the jump correlation frequency $\left(\tau_{1}^{-1}\right)$ vs. $T^{-1}$ determined for ball-milled $\mathrm{Na}_{2} \mathrm{~B}_{12} \mathrm{H}_{12}$ (blue symbols) compared to $\tau_{1}^{-1}$ values for pristine $\mathrm{Na}_{2} \mathrm{~B}_{12} \mathrm{H}_{12}$ (N.B., red symbols; adapted from Ref. [8] $\tau^{-1}$ values, where $\tau_{1}^{-1}=0.5 \tau^{-1}$ ).

Squares and circles denote measurements on DCS and HFBS instruments, respectively. All data points fit well to a single line with a preexponential factor of $2.2(2) \times 10^{13} \mathrm{~s}^{-1}$ and an activation energy for reorientation $E_{\mathrm{a}}$ (from the $-E_{\mathrm{a}} / k$ slope) of $270(3) \mathrm{meV}$.

expected [7]. QENS spectra of ball-milled $\mathrm{Na}_{2} \mathrm{~B}_{12} \mathrm{H}_{12}$ were measured between $270 \mathrm{~K}$ and $400 \mathrm{~K}$ and could be fit to a primary Lorentzian component linewidth $(2 \hbar) / \tau_{1}$, ranging between $0.27 \mu \mathrm{eV}$ and $11 \mu \mathrm{eV}$ fwhm, respectively. This narrow Lorentzian component dominated at lower $Q$ values, with increasing contributions from one and probably more broader Lorentzian components at larger $Q$ values, which is compatible with a smallangle jump mechanism [8]. Anion reorientational jump correlation frequencies derived 
from the QENS spectral broadening (Fig. 2b), are in excellent agreement with the Arrhenius dependence observed for pristine $\mathrm{Na}_{2} \mathrm{~B}_{12} \mathrm{H}_{12}$ above its phase transition at higher temperatures [8]. Combined data yield an activation energy for reorientation of 270(3) meV, the same value obtained for pristine bcc $\mathrm{Na}_{2} \mathrm{~B}_{12} \mathrm{H}_{12}$ from NMR measurements [9].

The measured elastic fraction of the total QENS spectrum (i.e., the elastic incoherent structure factor, EISF) at $400 \mathrm{~K}$ at $0.84 \AA^{-1}$ (with $11 \mu \mathrm{eV}$ resolution) was estimated to be $\sim 0.48$. Assuming a similar reorientational mechanism as for pristine disordered $\mathrm{Na}_{2} \mathrm{~B}_{12} \mathrm{H}_{12}$ [8], this EISF value is consistent with some small fraction (on the order of 20-25\%) of the anions being relatively immobile in an ordered monoclinic phase at this temperature. Moreover the further decrease in the FWS in Fig. 2a upon heating above $~ 340 \mathrm{~K}$ indicates that this remaining "immobile" phase fraction converts to the superionic phase over a broad temperature range until its completion above $500 \mathrm{~K}$. This transitioning fraction is reversible, as evidenced by the observed hysteretic FWS cooling behavior.

Since XRD results imply a much higher fraction of ordered phase, these dynamical results suggest that there is a significant fraction present of disordered amorphous or nanocrystalline phase invisible to diffraction and/or there are substantial contributions from "mobile" anions associated with a highly defective monoclinic phase. This is consistent with the NPD patterns for ball-milled $\mathrm{Na}_{2} \mathrm{~B}_{12} \mathrm{H}_{12}$ after the QENS measurements (see Fig. S9), which show a further increase in the crystalline bcc fraction, presumably from a slow coalescence of residual amorphous or nanocrystalline material during the (520 K maximum) FWS measurements. In addition, XRD patterns measured at elevated temperatures of $373 \mathrm{~K}$ and $438 \mathrm{~K}$ (not shown) indicated increasing fractions of bcc phase consistent with the reversible, temperature-dependent transformation of the immobile fraction seen in Fig. 2a. Even annealing at $620 \mathrm{~K}$ for $13 \mathrm{~d}$ led to a further increase in the apparent room- $T$ fraction of bcc phase (see Fig. S8). One might speculate that minute fractions of the anions may be changing by both ball-milling and such elevated temperatures (e.g., by polymerization or degradation of the cage-like structure) and somehow act as morphology-stabilizing defects.

Fig. 3 compares the ionic conductivities of $\mathrm{Na}_{2} \mathrm{~B}_{12} \mathrm{H}_{12}$ pre- and post-ball-milling. Fig. S13 and S14 display the corresponding complex impedance and cyclic voltammetry plots of the ball-milled material. The post-ball-milling conductivities were evaluated after performing the QENS (Fig. 2) and NPD (Fig. S9) measurements. It is clear that this limited degree of ball-milling already leads to about a four-orders-of-magnitude conductivity enhancement compared with pristine $\mathrm{Na}_{2} \mathrm{~B}_{12} \mathrm{H}_{12}$ below its $T_{\text {trans }}$ (and similar 
superionic conductivities above $\left.T_{\text {trans }}\right)$. Further conductivity enhancements are expected with increasing bcc fraction. The conduction activation energy is $0.21 \mathrm{eV}$ [3] for the pure superionic phase above $\sim 480 \mathrm{~K}$. Below this temperature, with respect to the ball-milled sample, the conductivity drops more rapidly with decreasing temperature, indicating that the activation energy is qualitatively larger in this mixed-phase region due to higher-barrier bottlenecks associated with the changing $T$-dependent fraction of ordered phase present.

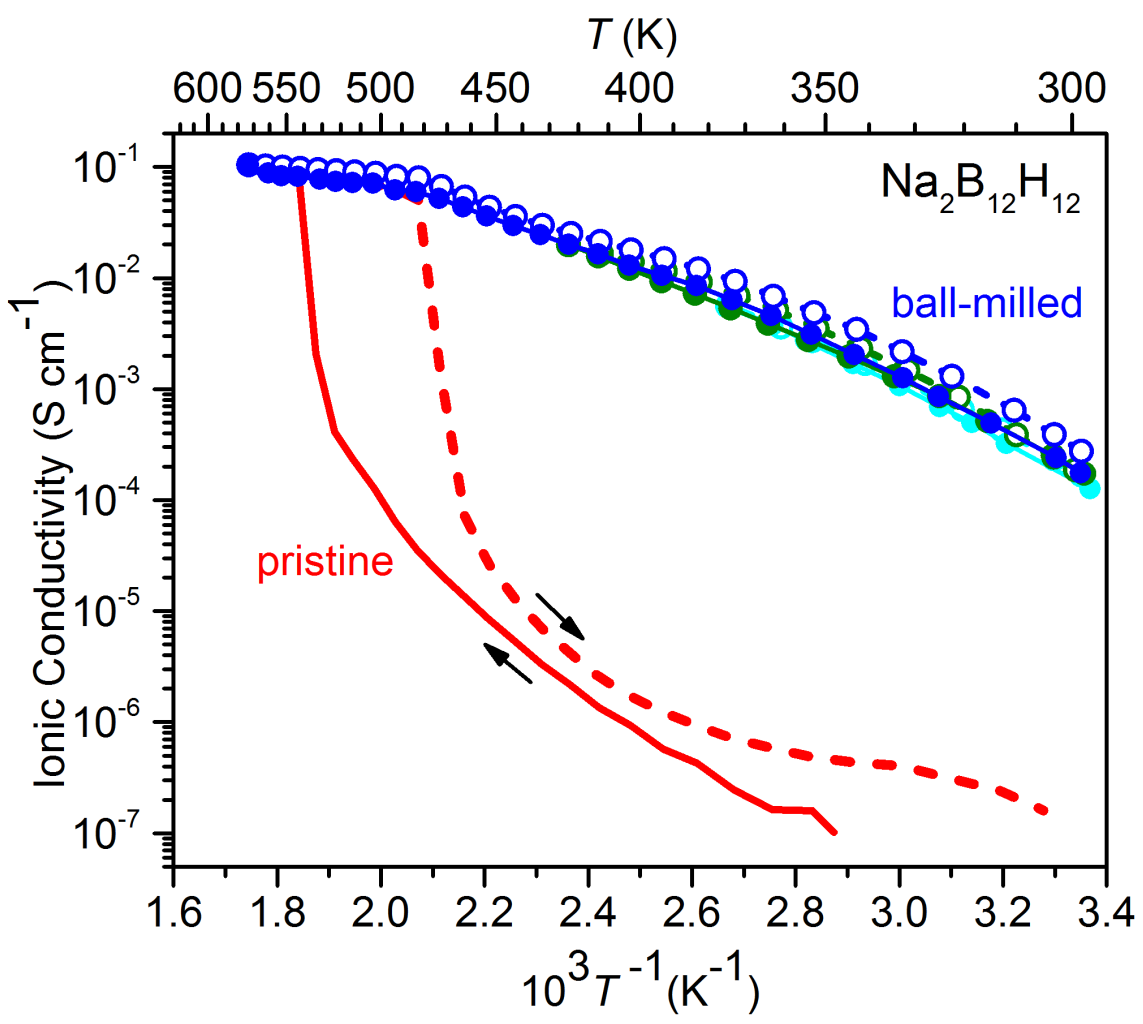

Fig. 3. Comparison of ionic conductivities for pristine [3] vs. ball-milled $\mathrm{Na}_{2} \mathrm{~B}_{12} \mathrm{H}_{12}$ after QENS measurements (see corresponding NPD patterns in Fig. S9). Closed and open symbols denote heating and cooling values, respectively. $1^{\text {st }}, 2^{\text {nd }}$, and $3^{\text {rd }}$ cycles: cyan, $(\leq 373 \mathrm{~K})$, green $(\leq 423 \mathrm{~K})$, and blue $(\leq 573 \mathrm{~K})$ symbols, respectively.

Fig. S15 exemplifies the ionic conductivity behavior for $\mathrm{Li}_{2} \mathrm{~B}_{12} \mathrm{H}_{12}$ as a function of ball-milling time (i.e., disordered phase fraction), and Fig. S13 displays the related complex impedance plot. Again ball-milling dramatically enhances conductivity, and, indeed, more extensive ball-milling leads to further improvement. Yet, unlike $\mathrm{Na}_{2} \mathrm{~B}_{12} \mathrm{H}_{12}$, the morphology (and conductivity) for $\mathrm{Li}_{2} \mathrm{~B}_{12} \mathrm{H}_{12}$ is obviously affected after repeated temperature cycling to only $413 \mathrm{~K}$. Thus, compared to $\mathrm{Na}_{2} \mathrm{~B}_{12} \mathrm{H}_{12}, \mathrm{Li}_{2} \mathrm{~B}_{12} \mathrm{H}_{12}$ appears to be less morphologically robust with respect to temperature. (This may well be a more general phenomenon concerning the relative morphological stabilities of $\mathrm{Na}$ and $\mathrm{Li}$ closo-borates, but this still needs to be resolved by further studies.) For $\mathrm{Li}_{2} \mathrm{~B}_{12} \mathrm{H}_{12}$ (and any other less morphologically robust compounds), it is likely essential to avoid 
excessively high temperatures or, e.g., resort to nanosequestration if one wants to effectively stifle sintering processes that would degrade lower- $T$ conduction properties within the lifecycle of an all-solid-state energy storage device.

It is evident from the XRD, QENS, and AC impedance measurements that ballmilling these materials leads to room- $T$ (and sub-room- $T$ ) stabilization of high- $T$-like disordered phases that typically only exist in the untreated bulk materials at more elevated temperatures. Although ball-milling-induced stresses and defects (vacancies, dislocations, stacking faults, grain boundaries, etc.) in the otherwise ordered room- $T$ crystal structures may themselves lead to enhanced cation mobility, the likely stabilization of high- $T$-like superionic phases due to crystallite-size reduction into the nanoscale regime cannot be ignored. The atoms in any crystallite surface layer will reconstruct in such a way as to minimize the crystallite surface energy, which can often lead to non-bulk-like thermodynamic behavior for nanoscale crystallites, such as the adoption of a normally higher- $T$ crystal structure [15] or a decrease in $T_{\text {trans }}[19,20]$. Although larger crystallites are dominated by their interior "bulk-like" region, the higher fraction of overall material associated with the surface of a polyhedral borate nanoparticle (which exhibits a large surface-to-bulk ratio as well as non-bulk-like finitesize effects) may translate into a higher fraction or complete stabilization of high-T-like disordered phase, if this phase has a lower surface energy. Compression of these powder materials would lead to a dense interconnecting conductive network of nanoparticles, allowing the cations to percolate through a continuum of facile pathways, even if these pathways are restricted to superionic nanoparticle surface layers surrounding more poorly conducting yet isolated crystallite interiors.

Lower- $T$ conductivities resulting from pelletized, lightly ball-milled $\mathrm{LiBH}_{4}$ were indeed reminiscent of the high values expected for its higher- $T$ hexagonal $(h)$ phase, but the broadened XRD pattern, was consistent with its low-T orthorhombic structure, with no clear evidence of a $h$-phase fraction [21]. This does not mean that the disorder and defects present in the material (particularly for nanosized particles and at the particle surfaces and grain boundaries) are not reflective of short-ranged hexagonal arrangements largely invisible to diffraction. Such nanoscale-driven modification, without the additional stresses and defects from ball-milling, is exemplified by the sequestration of $\mathrm{LiBH}_{4}$ in nanoporous carbon and silica via melt-infiltration $[20,22,23,24,25]$. In nanoporous carbon, NMR and QENS results $[20,22,24]$ indicated two fractions of $\mathrm{LiBH}_{4}$, a bulk-like fraction associated with the particle interiors and a more mobile fraction associated with the particle surface layers next to the pore walls. The latter fraction exhibited both enhanced $\mathrm{BH}_{4}{ }^{-}$anion reorientational and translational mobilities and $\mathrm{Li}^{+}$cation translational mobility, and this fraction increased with 
decreasing pore size (over the investigated pore diameter range of $\sim 25 \mathrm{~nm}$ to $2 \mathrm{~nm}$ ). The enhanced ion mobilities observed at room temperature for $\mathrm{LiBH}_{4}$ in both nanoporous carbon and silica were reminiscent of the presence of $h$ - $\mathrm{LiBH}_{4}[20,23]$, which is normally only stable above $\sim 390 \mathrm{~K}$. The more recent conductivity study [25] of $\mathrm{LiBH}_{4}$ in nanoporous silica indeed reported lower $T_{\text {trans }}$ values than for bulk $\mathrm{LiBH}_{4}$ and $h$-phase-like fast-ion conduction down to room temperature, but the high ionic mobility was attributed to $\mathrm{LiBH}_{4}$ likely near the pore interface, with no obvious phase transition. Again, this does not mean that this interface material was not also $h$-phase-like in character already at room temperature.

We note that particle-size reduction of a material by ball-milling or other means may not necessarily result in dramatically enhanced conductivity. There also must be a thermodynamic incentive to form an appropriately disordered phase, preferably one with cation vacancies. The nature of a material's high-T disordered structure may be a key predictor of its potential to form a room- $T$, nanocrystalline, fast-ion conductor. Also, for a bulk material that should hypothetically form a disordered structure, but is unable to do so due to decomposition or melting before attaining the necessary temperature, nanosizing may be a way to stabilize this otherwise unattainable or thermally unstable disordered structure. Indeed, $\mathrm{Li}_{2} \mathrm{~B}_{12} \mathrm{H}_{12}$ almost fits into this category, since its disordered phase is already rather unstable upon its formation above $615 \mathrm{~K}$ [7], whereas such a phase can be stabilized at much lower temperatures via ball-milling.

\section{Conclusion}

Pristine lithium and sodium salts with large polyhedral anion architectures have shown the capacity to form disordered phases with exceptional conductivities, yet only at somewhat elevated temperatures. These results clarify one strategy for stabilizing these superionic phases at room temperature and below. Crystallite-size-reduction processes such as ball-milling open the door for exploring further other possible superionic-phase-forming compounds based on this class of salts, including other cation substituents besides $\mathrm{Li}^{+}$and $\mathrm{Na}^{+}$and other related polyhedral anion substituents besides $\mathrm{B}_{12} \mathrm{H}_{12}{ }^{2-}, \mathrm{B}_{10} \mathrm{H}_{10}{ }^{2-}$, and $\mathrm{CB}_{11} \mathrm{H}_{12}{ }^{-}$, regardless of their $T_{\text {trans }}$ values. Moreover, new "alloy" compounds may result from ball-milling mixtures of these salts. Finally, the necessary nanosizing might also be accomplished in combination with or solely by other micronizing procedures such as spray drying or nanosequestration. These types of materials, with appropriate chemical and/or morphological modifications, merit further consideration as solid-state electrolyte materials in future energy-related devices. 


\section{References}

[1] (a) M. Matsuo, S. Orimo, Adv. Energy Mater. 1 (2011) 161-172; (b) A. Unemoto, M. Matsuo, S. Orimo, Adv. Funct. Mater. 24 (2014) 2267-2279.

[2] M. Matsuo, Y. Nakamori, S. Orimo, H. Maekawa, H. Takamura, Appl. Phys. Lett. 91 (2007) 224103.

[3] T.J. Udovic, M. Matsuo, A. Unemoto, N. Verdal, V. Stavila, A.V. Skripov, J.J. Rush, H. Takamura, S. Orimo, Chem. Commun. 50 (2014) 3750-3752.

[4] T.J. Udovic, M. Matsuo, W.S. Tang, H. Wu, V. Stavila, A.V. Soloninin, R.V. Skoryunov, O.A. Babanova, A.V. Skripov, J.J. Rush, A. Unemoto, H. Takamura, S. Orimo, Adv. Mater. 26 (2014) 7622-7626.

[5] W.S. Tang, A. Unemoto, W. Zhou, V. Stavila, M. Matsuo, H. Wu, S. Orimo, T.J. Udovic, Energy Environ. Sci. 8 (2015) 3637-3645.

[6] W.S. Tang, M. Matsuo, H. Wu, V. Stavila, W. Zhou, A.A. Talin, A.V. Soloninin, R.V. Skoryunov, O.A. Babanova, A.V. Skripov, A. Unemoto, S. Orimo, T.J. Udovic, Adv. Energy Mater. (2016) in press, http://dx.doi.org/10.1002/aenm.201502237.

[7] N. Verdal, J.-H. Her, V. Stavila, A.V. Soloninin, O.A. Babanova, A.V. Skripov, T.J. Udovic, J.J. Rush, J. Solid State Chem. 212 (2014) 81-91.

[8] N. Verdal, T.J. Udovic, V. Stavila, W.S. Tang, J.J. Rush, A.V. Skripov, J. Phys. Chem. C 118 (2014) 17483-17489.

[9] A.V. Skripov, O.A. Babanova, A.V. Soloninin, V. Stavila, N. Verdal, T.J. Udovic, J.J. Rush, J. Phys. Chem. C 117 (2013) 25961-25968.

[10] A.V. Skripov, R.V. Skoryunov, A.V. Soloninin, O.A. Babanova, W.S. Tang, V. Stavila, T.J. Udovic, J. Phys. Chem. C 119 (2015) 26912-26918.

[11] M. Paskevicius, M.P. Pitt, D.H. Brown, D.A. Sheppard, S. Chumphongphan, C.E. Buckley, Phys. Chem. Chem. Phys. 15 (2013) 15825-15828. 
[12] H. Wu, W.S. Tang, V. Stavila, W. Zhou, J.J. Rush, T.J. Udovic, J. Phys. Chem. C 119 (2015) 6481-6487.

[13] J.A. Teprovich Jr., H. Colón-Mercado, A.L. Washington II, P.A. Ward, S. Greenway, D.M. Missimer, H. Hartman, J. Velten, J.H. Christian, R. Zidan, J. Mater. Chem. A 3 (2015) 2285322859.

[14] (a) J. Huot, G. Liang, S. Boily, A.V. Neste, R. Schulz, J. Alloys Comp. 293-295 (1999) 495-500; (b) H.G. Schimmel, M.R. Johnson, G.J. Kearley, A.J. Ramirez-Cuesta, J. Huot, F.M. Mulder, J. Alloys Comp. 393 (2005) 1-4.

[15] J.M. McHale, A. Auroux, A.J. Perrotta, A. Navrotsky, Science 277 (1997) 788-791.

[16] R. Demir-Cakan, W.S. Tang, A. Darwiche, R. Janot, Energy Environ. Sci. 4 (2011) 3625-3631.

[17] J. Rodriguez-Carvajal, Physica B 192 (1993) 55-69.

[18] R.T. Azuah, L.R. Kneller, Y. Qiu, P.L.W. Tregenna-Piggott, C.M. Brown, J.R.D. Copley, R.M. Dimeo, J. Res. Natl. Inst. Stan. 114 (2009) 341-358.

[19] A.F. Gross, J.J. Vajo, S.L. Van Atta, G.L. Olson, J. Phys. Chem. C 112 (2008) 5651-5657.

[20] N. Verdal, T.J. Udovic, J.J. Rush, X. Liu, E.H. Majzoub, J.J. Vajo, A.F. Gross, J. Phys. Chem. C 117 (2013) 17983-17995.

[21] D. Sveinbjörnsson, J. S. G. Myrdal, D. Blanchard, J. J. Bentzen, T. Hirata, M. Bjerg Mogensen, P. Norby, S. Orimo, T. Vegge, J. Phys. Chem. C 117 (2013) 3249-3257.

[22] D.T. Shane, R.L. Corey, C. McIntosh, L.H. Rayhel, R.C. Bowman, Jr., J.J. Vajo, A.F. Gross, M.S. Conradi, J. Phys. Chem. C 114 (2010) 4008-4014.

[23] M.H.W. Verkuijlen, P. Ngene, D.W. de Kort, C. Barré, A. Nale, E.R.H. van Eck, P.J.M. van Bentum, P.E. de Jongh, A.P.M. Kentgens, J. Phys. Chem. C 116 (2012) 22169-22178.

[24] X. Liu, E.H. Majzoub, V. Stavila, R.K. Bhakta, M.D. Allendorf, D.T. Shane, M.S. Conradi, N. Verdal, T.J. Udovic, S.-J. Hwang, J. Mater. Chem. A 1 (2013) 9935-9941.

[25] D. Blanchard, A. Nale, D. Sveinbjörnsson, T.M. Eggenhuisen, M.H.W. Verkuijlen, Suwarno, T. Vegge, A.P.M. Kentgens, P.E. de Jongh, Adv. Funct. Mater. 25 (2015) 184-192. 